Even though the relationship between teaching and research has been examined extensively over the past decade, and a number of published articles and seminar based workshops exist (Hattie and Marsh, 1996); there continues to be a disconnect in the application and integration of these two concepts in the academic setting. This difficulty may be due to the perception that teaching and research are two separate entities that need to be fitted together (Boyer 1990). An alternative approach to understanding these two concepts is to envision them as one entity consisting of two components that feed off of each other. That is, as academics, our goal is to engage in a single entity identified as scholarly activities. These activities should present themselves as an amalgamation of teaching and research. To have a scholarly presence, an academic must not only be competent in both areas, but must consistently demonstrate the relationship between their teaching and research throughout their tenure. The purpose of this paper is to present an overview of strategies academics can consider as they continue to refine and develop their program of scholarship. A summary of the relationship between teaching and research will be provided, followed by a presentation of various methods that can enhance the teaching and research relationship both within and outside of the classroom environment.

\title{
Synergistic relationship between teaching and research
}

The dynamic, synergistic relationship between teaching and research has been discussed at length (Biggs and Tang, 2011; Boyer 1990; Glassick et al. 1997, Hattie and Marsh, 1996; Laurillard 2013), as well as the mutual benefits of building one's teaching dossier around their research foci, while continuing to develop and refine a program of research that addresses teaching process, content, and strategies. Boyer 
(1990) presented his scholarship model of teaching and learning, in which he argues that the synergistic relationship between teaching and learning provides an opportunity for the pedagogy of "research led teaching" to link teaching with research, while enhancing learning. The learning that Boyer refers to is one which is acquired by students and is generated through various research processes that include data searching, information processing and communication of knowledge and understanding. In essence, Boyer argues that research can benefit teaching; in that research led teaching can enhance knowledge and understanding of content resulting in improvement in knowledge acquisition, retention, recall, and application.

Research is "the systematic investigation into and study of materials and sources in order to establish facts and reach new conclusions" (Fellows and Liu, 2009, viii). Boyer (1990) argues that by considering teaching and research as one entity, it provides academics with the necessary skills to be able to search, synthesize, and critique the research literature to establish facts and reach new conclusions that can then be integrated within their curriculum to inform their teaching and evaluation methods. As researchers, one of the main skills that is developed is the ability to draw on and engage in critical reflective practices based on experiences, commonly referred to as experiential learning. Researchers will then use this acquired knowledge to gain a better understanding of findings obtained, design or revise study protocols, and/or resolve potential issues. Within the classroom setting, researchers who use this type of critical reflective process tend to be more effective in designing course materials as they are more likely to draw on experiential learning and engage in a critical reflective process thus allowing them to fully extract meanings, ideas, themes, as well as 
relevancy from course readings and theoretical materials. In essence, researchers who are actively involved in teaching should use their research skills to apply their critical thinking and problem-solving abilities to generate new conceptual knowledge, while incorporating pertinent philosophical principals throughout the facilitation process.

Furthermore, using this approach, academics should guide students to critically reflect on their own relevant experiences and existing course materials, identify main themes and then use these themes to assist in their understanding of lecture content (Hattie and Marsh, 1996). In doing so, students are taught key research skills related to reflection, extraction, and application and are provided with the opportunity to practice these skills in the context of teaching. Boyer (1990) states this activity provides students with the chance to develop transferable skills that are characteristic of advanced problem-solving, critical evaluation, and inter-personal skills which results in life-long learning.

Another key research skill that should be incorporated into teaching is that of publishing (Hattie and Marsh 1996). Publishing new and innovative approaches to teaching, reflections on existing teaching methods, or philosophical underpinnings of teaching are all potential areas that should be discussed on an ongoing basis. Similar to research, academics should consistently disseminate information pertaining to their teaching. As well, teaching should be informed by published works. Thus, the application of published findings to current teaching should form the basis for academics when engaged in the classroom.

In general, the quality of productivity generated by an academic is measured in terms of teaching effectiveness and research production. These outcomes are 
influenced by an individual's general ability to engage in both teaching and research

simultaneously. Because of the synergistic relationship between teaching and research, it is virtually impossible for an academic to be proficient in teaching without being involved in research. Using Boyer's (1990) theory as a frame of reference, one can argue that no matter how effective a faculty member may be rated in terms of their teaching, if they are not able to demonstrate the intermix between their teaching and research, then they have not satisfied their role as an academic. However, demonstrating this synergistic relationship can be challenging, as in many instances, academics are unaware and/or do not have the necessary skills to be able to adequately integrate these components into their program of scholarship. The remainder of this paper will present specific strategies academics can consider using to enhance and develop the ongoing synergistic relationship between teaching and research.

\section{Strategies to promote the relationship between teaching and research}

As discussed, research and teaching are intertwined. Thus, using research to inform one's teaching, and teaching to enlighten research should be an ongoing process in the life of an academic (Hattie and Marsh, 1996). However, this is not always possible, as many academics struggle with the unified concept of teaching and research. This in part may be due to the multi-faceted and dynamic relationship between each of these two entities; as well as the persistent intent to separate teaching and research by various institutions. This separation is evident through the creation of different funding schemes; as well as the individual assessment and evaluation of teaching and research which are often times examined as teaching quality and research 
output. To reinforce the integrated relationship between these two entities, more funding opportunities should incorporate criteria that demonstrate how both teaching and research are being integrated into the proposed funding application. For example, funding organizations should request applicants not only generate research proposals that are methodologically sound, but also embed within their proposal their plans for mentorship of students throughout the research process. As well, opportunities to fund teaching should request applicants identify how they will empirically examine the effectiveness of new and innovative teaching approaches both within and outside of the classroom setting.

Generating excitement for the research process within the classroom by incorporating the latest research on a specific topic into course lectures, designing learning activities around key research priorities, embedding the teaching of various aspects of the research method process into various segments of courses, integrating mini research activities into course assignments or in-class group activities, encouraging students to participate in faculty members' research projects either as paid employment or for volunteer experience, and drawing on research findings that reflect student success to make changes in curriculum redesign. Conversely, stimulating discussions generated throughout classroom interactions can lead to new areas for research (Hattie and Marsh, 1996).

Academics should be aware of the various opportunities that can be used to connect their teaching with their research and vice versa. In doing so, they will not only enhance their overall program of scholarship, but will also improve the student learning and engagement experience. 


\section{References}

Biggs J, Tang C (2011) Teaching for quality learning at university. New York, McGrawHill International

Boyer E (1990) Scholarship reconsidered: Priorities of the professoriate. New Jersey, Princeton University Press

Fellows R, Liu A (2009) Research methods for construction. John Wiley \& Sons, 2009.

Glassick C, Huber M, Maeroff G (1997) Scholarship Assessed: Evaluation of the Professoriate. Special Report. San Francisco, Jossey Bass Inc

Hattie J, Marsh H (1996) The relationship between research and teaching: A metaanalysis. Review of educational research 66(4): 507-542.

Laurillard D (2013) Rethinking university teaching: A conversational framework for the effective use of learning technologies. Routledge 